\title{
Gambaran Determinan Pemberian ASI Eksklusif pada Ibu dengan Bayi Usia 6-24 Bulan
}

\author{
Siti Maesaroh ${ }^{(1 *)}$, Ani Kristianingsih ${ }^{(2)}$, Heni Anggraini ${ }^{(3)}$ \\ 1,2,3 Program Studi Kebidanan, STIKes Aisyah Pringsewu, Lampung, 35372, Indonesia \\ ${ }^{\left({ }^{*}\right)}$ sitimaes1986@ gmail.com; ${ }^{(2)}$ anikristianingsih504@yahoo.com $;{ }^{(3)}$ anggraini.1506@yahoo.com
}

\begin{tabular}{l} 
ARTICLE INFO \\
\hline Article history: \\
Received 10 January 2018 \\
Revised 02 April 2018 \\
Accepted 02 April 2018 \\
\end{tabular}

Keyword:

Exclusive Breast Milk

Knowledge

Attitude

Husband Support

Health Officer Support

*) corresponding author

DOI:http://dx.doi.org/10.30604/jika.v3i1.68

\section{A B S T R A C T}

One indicator to know the health status in a country can be seen from the high Infant Mortality Rate (IMR). The main cause of infant death is due to respiratory tract infections and diarrhea. According to the World Health Organization (WHO) that acute pneumonia cases, 55 percent of infant deaths due to diarrhea due to lack of exclusive breastfeeding in the first six months at the beginning of the baby's life. The success of exclusive breastfeeding programs can create a golden generation (golden Period) which at that age happens optimal growth process. This study aims to determine the description of the determinant of exclusive breastfeeding in the mother in Wonosari Village, Subdistrict of Gadingrejo. This research type is quantitative research by using descriptive method. The samples used were 92 mothers who had babies 6-24 months old. From the results of the study, it was found that the distribution of respondents who gave exclusive breastfeeding as many as 48 people (52.2 percent), and who did not give exclusive milk as many as 44 people (47.8 percent). Respondents have a good knowledge about exclusive breastfeeding as many as 63 people (68.5 percent). Respondents had a positive attitude toward exclusive breastfeeding of 33 people (35.9 percent). Respondents who received husband support in exclusive breastfeeding as many as 26 people (28.3 percent). Respondents who received the support of health officers to exclusive breastfeeding were 56 people (60.9 percent). The results of this study can be used as guidelines to formulate strategies in providing information about health, especially about the importance of exclusive breastfeeding in an effort to increase the achievement of exclusive breastfeeding coverage to 100 percent, so that by itself will reduce the IMR.

Copyright (C) 2018, Jurnal Aisyah: Jurnal Ilmu Kesehatan. All rights reserved.

\section{PENDAHULUAN}

Salah satu indikator untuk mengetahui status kesehatan masyarakat di suatu negara dapat dilihat dari tingginya Angka Kematian Ibu (AKI) dan Angka Kematian Bayi (AKB). Penyebab utama kematian 
bayi adalah karena penyakit infeksi yaitu infeksi saluran pernafasan dan diare. Estimasi menurut World Health Organization (WHO) bahwa 53 persen kasus pneumonia akut, 55 persen kematian bayi akibat diare dikarenakan pemberian makanan yang buruk pada enam bulan pertama kehidupan (Gupta, 2013). Salah satu upaya dalam menurunkan AKB adalah dengan memberikan Air Susu Ibu (ASI) eksklusif. ASI Memiliki kandungan nutrisi yang lengkap selain didalam ASI juga terdapat zat kekebalan seperti $\operatorname{IgA}, \operatorname{IgM}$ ,IgG, IgE, laktoferin, lisosom, immunoglobulin dan zat lainnya yang melindungi bayi dari berbagai penyakit infeksi (Moehji, 2008). ASI eksklusif artinya bahwa bayi hanya diberi ASI saja tanpa tambahan cairan lain seperti susu formula,jeruk, madu, air teh, dan air putih, dan juga tanpa tambahan makanan padat seperti, pisang, pepaya, bubur susu, biskuit, bubur nasi dan nasi tim mulai lahir sampai usia 6 bulan (Roesli, 2009). Lebih dari 136 juta bayi lahir setiap tahunnya, dan sekitar 92 juta diantaranya tidak mendapatkan ASI eksklusif sampai 6 bulan (Gupta, 2013).

Berdasarkan data Riset Kesehatan Dasar (Riskesdas, 2013) pemberian ASI eksklusif pada bayi usia $0-1$ bulan 48,7 persen, pada usia 2-3 bulan menurun menjadi 42,2 persen dan semakin menurun seiring dengan meningkatnya usia bayi yaitu 36,6 persen pada bayi berusia 4-5 bulan dan 30,2 persen pada bayi usia 6 bulan. Pada tahun 2009 pencapaian cakupan ASI eksklusif sebesar 34,3 persen dan menurun pada 2010 menjadi 33,6 persen (BPS, Susenas 2010). Sedangkan Hasil Riset Kesehatan Dasar tahun 2013 jauh lebih rendah lagi yaitu 30,2 persen. (Riskesdas, 2013). Angka tersebut masih jauh dari target cakupan ASI nasional yaitu sebesar 80 persen. Hal ini tentu sangat memprihatinkan mengingat Indonesia merupakan salah satu negara yang memiliki kebijakan tentang ASI yang cukup baik serta upaya- upaya program akselerasi untuk pencapaian ASI eksklusif yang sangat gencar baik dilakukan oleh pemerintah, swasta maupun Lembaga Swadaya Masyarakat (LSM).

Salah satu penyebab rendahnya pemberian ASI di Indonesia adalah kurangnya pengetahuan ibu hamil, keluarga dan masyarakat akan pentingnya ASI. Masalah ini diperparah dengan gencarnya promosi susu formula dan kurangnya dukungan dari masyarakat, termasuk institusi yang mempekerjakan perempuan yang belum memberikan tempat dan kesempatan bagi ibu menyusui di tempat kerja (Depkes RI, 2011). Selain itu masih rendahnya cakupan pemberian ASI Eksklusif dipengaruhi beberapa hal terutama masih terbatasnya tenaga konselor menyusui di fasilitas pelayanan kesehatan, belum maksimalnya kegiatan edukasi, advokasi, dan kampanye terkait pemberian ASI maupun MP-ASI, Ketersediaan sarana dan prasarana KIE ASI dan MP-ASI serta belum optimalnya pembinaan kelompok pendukung ibu menyusui (Pekan ASI Sedunia, 2013).

\section{METODE}

Jenis penelitian ini adalah penelitian kuantitatif dengan menggunakan metode deskriptif. Penelitian ini bertujuan untuk mengetahui gambaran determinan Pemberian ASI eksklusif Pada ibu di Desa Wonosari Kecamatan Gadingrejo Tahun 2017.

Populasi dalam penelitian ini adalah seluruh ibu menyusui di desa Wonosari yang memiliki bayi usia 6-24 bulan yaitu sebanyak $120 \mathrm{ibu}$. Sampel yang digunakan saat penelitian adalah sebanyak $92 \mathrm{ibu}$ yang memiliki bayi usia 6-24 bulan.

Pengumpulan data pada penelitian ini menggunakan data primer atau langsung dari responden yaitu melalui angket yang dibagikan kepada responden. Setelah data terkumpul maka dilakukan pengolahan data melalui pengecekan kelengkapan data, skoring dan tabulasi data kemudian dilakukan analisa data dengan menggunakan analisis univariat. Analisa 
data ini dilakukan untuk mendiskripsikan beberapa variabel penelitian, data hasil penelitian disajikan dalam bentuk tabel distribusi frekuensi.

\section{HASIL DAN PEMBAHASAN}

Berdasarkan tabel 1 dapat diketahui bahwa distribusi responden yang memberikan ASI Eksklusif yaitu sebanyak 48 orang (52.2 persen), dan multipara sebanyak 44 orang (47.8 persen).

Tabel 1. Distribusi Frekuensi Pemberian ASI Eksklusif

\begin{tabular}{ccc}
\hline ASI Eksklusif & Frekuensi & Persentase (\%) \\
\hline Tidak & 44 & 47.8 \\
\hline Ya & 48 & 52.2 \\
\hline Total & $\mathbf{9 2}$ & $\mathbf{1 0 0 . 0}$ \\
\hline
\end{tabular}

Berdasarkan tabel 2 dapat diketahui bahwa sebagian besar responden memiliki pengetahuan yang baik tentang ASI eksklusif yaitu sebanyak 63 orang (68.5 persen) sedangkan yang responden yang memiliki pengetahuan kurang baik sebanyak 29 orang (31.5 persen).

Tabel 2. Distribusi Frekuensi Pengetahuan Ibu Tentang ASI Eksklusif

\begin{tabular}{ccc}
\hline Pengetahuan & Frekuensi & Persentase $(\%)$ \\
\hline Kurang Baik & 29 & 31.5 \\
\hline Baik & 63 & 68.5 \\
\hline Total & $\mathbf{9 2}$ & $\mathbf{1 0 0 . 0}$ \\
\hline
\end{tabular}

Berdasarkan tabel 3 dapat diketahui bahwa sebagian besar responden memiliki sikap negatif terhadap ASI eksklusif yaitu sebanyak 59 orang (64.1 persen) sedangkan responden yang memiliki sikap positif terhadap ASI eksklusif sebanyak 33 orang (35.9 persen).

Tabel 3. Distribusi Frekuensi Sikap Ibu

\begin{tabular}{ccc}
\hline Sikap & Frekuensi & Persentase (\%) \\
\hline Negatif & 59 & 64.1 \\
\hline Positif & 33 & 35.9 \\
\hline Total & $\mathbf{9 2}$ & $\mathbf{1 0 0 . 0}$
\end{tabular}

Berdasarkan tabel 4 dapat diketahui bahwa sebagian besar responden tidak mendapat dukungan suami terhadap pemberian ASI eksklusif yaitu sebanyak 66 orang (71.7 persen) sedangkan responden yang mendapat dukungan suami terhadap ASI eksklusif sebanyak 26 orang (28.3 persen).

Tabel 4. Distribusi Frekuensi Dukungan Suami Terhadap Pemberian ASI

\begin{tabular}{ccc}
\hline $\begin{array}{c}\text { Dukungan } \\
\text { Suami }\end{array}$ & Frekuensi & Persentase (\%) \\
\hline $\begin{array}{c}\text { Tidak } \\
\text { Mendukung }\end{array}$ & 66 & 71.7 \\
\hline Mendukung & 26 & 28.3 \\
\hline Total & $\mathbf{9 2}$ & $\mathbf{1 0 0 . 0}$ \\
\hline
\end{tabular}

Berdasarkan tabel 5 dapat diketahui bahwa sebagian besar responden mendapat dukungan petugas kesehatan terhadap pemberian ASI eksklusif yaitu sebanyak 56 orang (60.9 persen) sedangkan responden yang mendapat dukungan petugas kesehatan terhadap ASI eksklusif sebanyak 36 orang (39.1 persen).

Tabel 5. Distribusi Frekuensi Dukungan Petugas Kesehatan terhadap pemberian ASI Eksklusif

\begin{tabular}{ccc}
\hline $\begin{array}{c}\text { Dukungan Petugas } \\
\text { Kesehatan }\end{array}$ & Frekuensi & $\begin{array}{c}\text { Persentase } \\
(\mathbf{\%})\end{array}$ \\
\hline Tidak Mendukung & 36 & 39.1 \\
\hline Mendukung & 56 & 60.9 \\
\hline Total & $\mathbf{9 2}$ & $\mathbf{1 0 0 . 0}$ \\
\hline
\end{tabular}

\section{Pemberian ASI Eksklusif}

Dari hasil Penelitian diperoleh bahwa distribusi responden yang memberikan ASI Eksklusif yaitu sebanyak 48 orang (52.2 persen), dan yang tidak memberikan ASI Eksklusif sebanyak 44 orang (47.8 persen). Hal ini menggambarkan adanya kesadaran ibu tentang pentingnya pemberian ASI Eksklusif. ASI merupakan makanan yang tepat bagi bayi, karena ASI merupakan makanan yang mudah dicerna oleh bayi, selain itu kandungan gizinya yang komplek akan terserap secara optimal untuk pemenuhan kebutuhan bayi dan juga pemberian ASI sangat menentukan bayi tumbuh dan berkembang dengan baik. 


\section{Pengetahuan Ibu Tentang ASI Eksklusif}

Hasil penelitian menunjukan bahwa sebagian besar responden memiliki pengetahuan yang baik tentang ASI eksklusif yaitu sebanyak 63 orang (68.5 persen) sedangkan yang responden yang memiliki pengetahuan kurang baik sebanyak 29 orang (31.5 persen). Hal ini dapat terjadi karena dukungan petugas kesehatan baik dari bidan desa, puskesmas, dinas kesehatan kabupaten sampai dinas kesehatan propinsi yang terjun langsung dalam memberikan informasi kesehatan khususnya tentang pentingnya pemberian ASI Eksklusif sehingga pengetahuan masyarakat tentang pentingnya pemberian ASI Eksklusif meningkat.

Peneliti berpendapat bahwa langkah sosialisasi tentang penting dan tidaknya pemberian ASI Eksklusif telah dilaksanakan sesuai rencana yang telah ditetapkan namun dalam prose situ tidak semua ibu dapat mengakses informasi tersebut yang dipengaruhi oleh banyak faktor. Oleh karena itu mengantisipasi hal tersebut perlu dilakukan teknik yang lebih efektif dalam pemberian informasi kepada sasaran (ibu hamil dan ibu bersalin) dengan mengajak masyarakat berpatisipasi aktif dalam pemberian informasi tentang penting dan tidaknya pemberian ASI eksklusif, baik secara individu (tokok masyarakat, tokoh agama, tokoh adat) atau secara formal (TP PKK) atau kelom[ok-kelompok lainnya. Pemberian informasi dilakukan secara tepat dengan cara sweeping ibu hamil atau mendata ibu hamildan menentukan jadual ANC nya kemudian memberikan materi tentang pentingnya mempersiapkan ASI agar dapat sukses dalam pemberian ASI Eksklusif kepada bayi.

\section{Sikap Ibu Terhadap pemberian ASI Eksklusif}

Hasil penelitian menunjukan bahwa sebagian besar responden memiliki sikap negatif terhadap ASI eksklusif yaitu sebanyak 59 orang (64.1 persen) sedangkan responden yang memiliki sikap positif terhadap ASI eksklusif sebanyak 33 orang (35.9 persen). Sikap merupakan proses afeksi yang di dalamnya, seseorang sudah melakukan perbandingan dari berbagai informasi yang diperolehnya. Jika hasil perbandingan informasi dari apa yang diketahui tersebut baik maka sikapnya terhadap ASI eksklusif juga menjadi positif, demikian juga sebaliknya. Sikap positif merupakan salah satu bentuk dukungan seseorang terhadap pemberian ASI eksklusif, hal ini karena berdasarkan apa yang dirasakannya pemberian ASI eksklusif dapat memberikan manfaat untuk dirinya, sementara sikap negatif muncul karena pertimbangan bahwa pemberian ASI eksklusif akan memberikan dampak yang kurang baik bagi sang Ibu.

Hasil penelitian memposisikan sikap sebagai salah satu faktor yang juga memberikan kontribusi terhadap individu dalam merespons sesuatu (pemberian ASI eksklusif), oleh karena sikap berwujud perasaan atau emosi maka pengetahuan tentang pemberian ASI eksklusif harus ditingkatkan melalui sosialisasi tentang penting dan tidaknya pemberian ASI eksklusif, pemberian pelayanan kepada pasien dan lain sebagainya.

Intervensi yang dapat dilakukan kepada ibu hamil berkaitan dengan pembentukan sikap sama dengan langkah dalam intervensi pengetahuan melalui pendataan lengkap ibu hamil di setiap wilayah dan melakukan kunjungan kepada ibu hamil untuk memberikan konseling tentang jaminan kesehatan yang ada beserta syarat-syarat yang harus dipenuhi. Dengan demikian jika ibu dan keluarga memahami bukan saja hanya sekedar tahu, diharapkan mereka mampu membuat keputusan dalam menggunakan haknya. Pembagian wilayah untuk pendataan dilakukan berdasarkan kluster terkecil yang menjadi tanggung jawab bidan setempat, sehingga hal ini dimaksudkan untuk meringankan tugas bidan di wilayah tersebut. 


\section{Dukungan Suami terhadap pemberian ASI Eksklusif}

Hasil penelitian menunjukan bahwa sebagian besar responden tidak mendapat dukungan suami terhadap pemberian ASI eksklusif yaitu sebanyak 66 orang (71.7 persen) sedangkan responden yang mendapat dukungan suami terhadap ASI eksklusif sebanyak 26 orang (28.3 persen).

Hasil penelitian ini didukung penelitian Bernadus dkk (2013) menjelaskan bahwa tingginya angka pemberian ASI eksklusif pada bayi karena dukungan pasangan atau suami, karena suami juga menyadari pentingnya pemberian ASI eksklusif.

Berdasarkan penjelasan tersebut maka penulis berpendapat bahwa dukungan suami dapat dikatakan sebagai salah satu faktor pemungkin, yang memungkinkan suatu motivasi atau aspirasi terlaksana, Hal ini dikarenakan suami merupakan keluarga inti dari istri yang secara langsung memiliki interaksi dengan anak untuk memberikan ASI eksklusif.

\section{Dukungan Petugas Kesehatan Terhadap Pemberian ASI Eksklusif.}

Hasil penelitian menunjukan bahwa sebagian besar responden mendapat dukungan petugas kesehatan terhadap pemberian ASI eksklusif yaitu sebanyak 56 orang (60.9 persen) sedangkan responden yang mendapat dukungan petugas kesehatan terhadap ASI eksklusif sebanyak 36 orang (39.1 persen).

Ibu yang tidak mendapat dukungan tersebut tergambar dari minimnya informasi yang diperoleh, pada saat melakukan kunjungan ke bidan ibu tidak mendapatkan informasi tentang penting dan tidaknya pemberian ASI eksklusif, atau tidak ditawarkan untuk memanfaatkan ASI eksklusif. Sementara ibu yang merasa didukung oleh petugas kesehatan adalah karena telah mendapatkan informasi lengkap tentang manfaat dari ASI eksklusif untuk bayi meraka.
Secara konseptual Notoatmojo (2007), menjelaskan bahwa dukungan petugas kesehatan dapat berupa penyuluhan kesehatan, adalah sejumlah pengalaman yang berpengaruh secara menguntungkan terhadap kebiasaan, sikap dan pengetahuan yang ada hubungannya dengan kesehatan perorangan, masyarakat. Oleh karena itu adanya penyuluhan kesehatan khususnya tentang pemberian ASI eksklusif bertujuan untuk merubah perilaku masyarakat dalam memanfaatkan pelayanan kesehatan yang ada.

Penelitian Mariyah (2005) menyimpulkan hal yang serupa tentang pentingnya dukungan petugas kesehatan dalam membentuk atau merubah perilaku karena hasil penelitiannya menununjukkan bahwa ada hubungan antara penyuluhan oleh tenaga kesehatan dengan pemberian ASI eksklusif. Jika dikaitkan dengan teori Green (1980) penyuluhan oleh petugas kesehatan termasuk sebagai faktor penguat yang dapat mendorong menguatnya atau melemahnya perilaku kesehatan. Kurangnya pembinaan dalam bentuk penyuluhan kepada masyarakat baik kunjungan berkala ke rumah untuk melakukan pemantauan tentang kehamilan ibu. Oleh karenanya perlu dilakukan penyuluhan secara lebih kontinyu dan lebih penting lagi kalau penyuluhan dilakukan secara personal dengan melakukan kunjungan langsung bidan kepada masyarakat untuk memantau, memfasilitasi, serta menawarkan solusi dari permasalahn yang muncul dalam keluarga yang menghambat terwujudnya pemberian ASI eksklusif.

\section{KESIMPULAN}

Hasil penelitian dapat dijadikan pedoman untuk menyusun strategi dalam memberikan informasi tentang kesehatan khususnya tentang pentingnya pemberian ASI eksklusif dalam upaya meningkatkan pencapaian cakupan ASI eksklusif menjadi 100 persen ditahun 2018, sehingga dengan 
sendirinya akan menurunkan $\mathrm{AKB}$, selain itu keberhasilan ASI eksklusif dapat menciptakan generasi emas (golden Period) dimana pada usia tersebut terjadi proses tumbuh kembang yang optimal.

Saran yang dapat diberikan dari hasil penelitian yang telah dilakukan adalah Petugas sebaiknya memberikan informasi yang lengkap kepada ibu yang memiliki bayi tentang pentingnya ASI eksklusif bagi perkembangan dan pertumbuhannya.

Puskesmas juga perlu melakukan sosialisasi dengan memberikan brosur pamflet dan leaflet serta melakukan pengontrolan lebih ketat pada ibu berkaitan dengan gizi yang seharusnya dikonsumsi bayi usia 0-6 bulan . Puskesmas juga diharapkan dapat membuat program untuk meningkatkan pemberian ASI eksklusif pada ibu menyusui, memberikan penyuluhan kepada ibu hamil tentang persiapan menyusui dan pemantauan pemberian ASI setelah ibu melahirkan dan meningkatkan peran serta suami dan orang tua dalam kelompok pendukung ASI eksklusif.

Petugas Kesehatan dapat meningkatkan kemampuan untuk memberikan penyuluhan kepada ibu untuk pemberian ASI eksklusif. Petugas kesehatan hendaknya memberikan penyuluhan ASI eksklusif sejak ibu hamil, tentang pengertian ASI eksklusif, manfaat ASI, tanda bayi kecukupan ASI dan cara penyimpanan ASI. Melakukan insiasi dini pada pertolongan persalinan dan melakukan pemantauan pelaksanaan ASI eksklusif pada ibu menyusui.

Ibu yang memiliki bayi yang bekerja di luar rumah agar tetap memberikan ASI Eksklusif pada bayinya dengan cara memeras ASI-nya sebelum berangkat kerja dan disimpan pada tempat yang steril. Pengetahuan tentang kolostrum lebih ditingkatkan dan sebaiknya ibu yang memiliki bayi, belajar dari pengalaman sebelumnya agar pemberian ASI Eksklusif lebih ditingkatkan. 


\section{DAFTARA PUSTAKA}

Abdullah, G.I., Ayubi. D. (2013). Determinan Perilaku Pemberian Air Susu Ibu Eksklusif pada Ibu Pekerja. Jurnal Kesehatan Masyarakat Nasional 7.7.

Arikunto, Suharsini. (2007). Prosedur Penelitian Suatu Pendekatan Praktik. Jakarta: Rineka Cipta.

Breastfeeding Support: Close To Mother. (2013). Pekan ASI Sedunia tahun 2013. Diakses 23 April 2016

Dharma,Kelana Kusuma. (2011). Metode Penelitian Keperawatan. Jakarta: Trans Info Media.

Departemen Kesehatan. (2011). Banyak Sekali Manfaat ASI Bagi Bayi dan Ibu. Diakses pada diakses tanggal 10 Februari 2015

Dirjen Bina Gizi dan KIA. (2014). Materi Penyuluhan Pemberian ASI Eksklsusif dan Makanan Pendamping ASI. Jakarta: Kemenkes.

Dirjen Bina Gizi dan KIA. (2012). Panduan Pelatihan Konseling Pemberian Makanan Bayi dan Anak. Jakarta: Kemenkes RI.

Gupta A., Padhich, J. P., Suri, S. (2013). How Global Rates of Exclusive Breastfeeding For The First 6 Months Be Enhanced. ICAN. Vol 5 No.3: 133-140,

Kementerian Kesehatan RI. (2012). Peraturan Pemerintah Republik Indonesia Nomor 33 Tahun 2012 Tentang Pemberian Air Susu Ibu Eksklusif. Jakarta: Kemenkes RI.

Kementerian Kesehatan RI. (2014). Riset kesehatan dasar 2013. Jakarta: Kementrian Kesehatan RI.
Moehji, Sjahmien. Bayi Sehat dan Cerdas Melalui Gizi dan Makanan Pilihan Pedoman Asupan Gizi Untuk Bayi dan Balita. Jakarta: Pustaka Mina.

Notoatmojo, S. (2007). Promosi Kesehatan dan Ilmu Perilaku. Jakarta: Rineka Cipta.

Notoatmojo, S. (2010). Ilmu Perilaku Kesehatan. Jakarta: Rineka Cipta.

Notoatmojo, S. (2012). Ilmu Perilaku Kesehatan. Jakarta: Rineka Cipta.

Nurpelita. (2007). Faktor-Faktor yang Berhubungan dengan Pemberian ASI Eksklusif di Wilayah Kerja Puskesmas Buatan II Siak tahun 2007. Depok: Tesis FKM UI.

Ramadhani,M. Hadi. E.N. (2009). Dukungan Suami dalam Pemberian ASI Eksklusif di Wilayah Kerja Puskesmas Air Tawar Kota Padang, Sumatera Barat. Jurnal Kesehatan Masyarakat Nasional. Vol.4 no 6. 2010.

Roesli, Utami. (2009). Mengenal ASI Ekslusif, Jakarta.

Sugiono. (2010). Metode penelitian kuantitatif dan kualitatif. Jakarta: Alfabeta.

Swandari. S. (2013). Manajemen Laktasi Bagi Ibu Bekerja. Kemenkes RI. Diakses tanggal 23 April 2016

Prasetyono, D. S. (2009). Buku Pintar ASI Eksklusif. Jilid 1. Yogjakarta: Diva Press (Anggota IKAPI).

WHO/UNICEF/USAID. (2008). Indicators for assessing infant and young child feeding practices. Geneva: World Health Organization.

Wiji, R. Natia. (2013). ASI dan Panduan Ibu menyusui. Yogyakarta: Nuha Medika. 
J urnal Aisyah: J urnal Ilmu Kesehatan, 3(1), J uni 2018, - 16

Siti Maesaroh, Ani Kristianingsih, Heni Anggraini 